EVS25

Shenzhen, China, Nov 5-9, 2010

\title{
Design and Implementation of a Smart Lithium-Ion Battery Capacity Estimation System for E-Bike
}

\author{
Yow-Chyi Liu ${ }^{1}$, Shyue-Bin Chang ${ }^{2}$ \\ ${ }^{I}$ Department of Electrical Engineering, Kao Yuan University \\ ${ }^{2}$ Department of Mechanical and Automation Engineering, Kao Yuan University \\ No.1821, Jhongshan Rd., Lujhu Township, Kaohsiung County 821, Taiwan, R.O.C. \\ E-mail:liuyc@cc.kyu.edu.tw
}

\begin{abstract}
This paper proposes a smart lithium-ion battery capacity estimation method for electric bicycles. Battery capacity information informs the electric vehicle driver of the residual battery working time, thus facilitating the estimation of mileage of electric bicycle and timing of battery charging to avoid overcharging or over-discharging. Factors such as different discharge rates, environmental temperature, battery charge and discharge efficiency and battery aging affect the released capacity of battery, which is an electrochemical reaction of battery. In addition to integrating the advantages of the coulometric measurement and open circuit voltage measurement methods, and the proposed smart lithium-ion battery capacity estimator also incorporates discharge current, temperature, battery aging, as well as charging efficiency factors into capacity correction to develop a highly accurate PIC single-chip lithium-ion battery capacity estimation system.
\end{abstract}

Keywords: Lithium-ion battery, coulometric measurement, open circuit voltage, state of charge

\section{Introduction}

Despite their convenience in modern life, automotive vehicles operate on fuel oil, emitting carbon dioxide that poses a threat to human health, exacerbates the greenhouse effect and contributes to global warming. Environmental protection has received increasing emphasis in recent years, explaining the concentrated efforts to develop electric vehicles without exhaust emissions and increased energy efficiency than conventional automotive vehicles.

Battery capacity information informs electric vehicle drivers of the current state of charge (SOC) to remain aware of the battery's remaining operational time and to estimate the mileage in order to determine when to charge the battery. Multiplying the battery residual capacity (Wh) with the energy consumption factor of an electric vehicle $(\mathrm{km} / \mathrm{Wh})$ allows drivers to accurately predict the mileage of electric vehicles based on the current battery capacity [1-3].

Estimating the battery capacity further allows electric vehicle drivers to avoid battery overcharging and over-discharging in order to extend the battery service life. Estimation method of battery residual capacity includes direct a discharge test [4], open circuit voltage measurement [5-6], internal resistance measurement [7], coulometric measurement [8-9], loaded voltage measurement [10], electrolyte concentration measurement [10], coup de fouet effect [11], peulert equation estimation [12], artificial neural network [13], and fuzzy control [14]. 
Common secondary battery categories include lead-acid battery, lithium-ion battery, Ni-MH battery and Ni-Cd battery. In these secondary battery categories, lithium-ion battery possesses high energy density and other advantages, including light weight, thin thickness, miniaturized size, long service life, high-current discharge, small memory effect, high output potential as well as various sizes. Therefore, demand for lithium batteries is increasing annually, as found in portable products such as digital cameras, mobile phones and notebook computers. Lithium-ion battery is thus adopted in the development of electric bicycles owing to light weight considerations.

Lithium-ion batteries in electric bicycles significantly differ from those in other products such as mobile phones, notebook computers and uninterruptible power supply systems. As a bicycle battery operates continuously in a short period, battery capacity is normally designed to allow drivers to operate for around 1-2 hours. As the battery power is exhausted, the driver must charge the battery.

Based on electric bicycle usage features, an electric bicycle is driven around one or two hours daily; the battery is thus largely in an off mode. Therefore, the open circuit voltage method is quite feasible for estimating the initial capacity of batteries. Despite its high accuracy, the open circuit voltage method can only estimate the initial capacity accurately but can not provide an accurate battery capacity during its discharging process. Therefore, once charging or discharging is operated, the battery requires a rest period before the capacity of battery can respond to the output voltage of battery.

Coulometric measurement is currently considered as a highly accurate method. Although coulometric measure-ment allows us to estimate the battery capacity accurately, it unfortunately generates a large accumulative error if used for a long period of time. Therefore, this paper adopts both the open circuit voltage method and coulometric measurement method coordinately. Additionally, precisely estimating the lithium-ion battery capacity involves consideration of the current effect, battery temperature, battery aging and charging efficiency.

\section{Power Supply System for E-Bike}

\subsection{Lithium-ion Battery}

This paper adopts Molicel IMR18650A and IBR26700A lithium-ion batteries as examples. A single IMR $18650 \mathrm{~A}$ cell is $3.8 \mathrm{~V} / 2.9 \mathrm{AH}$, with weight energy density of $110 \mathrm{Wh} / \mathrm{kg}$, volume energy density of $285 \mathrm{Wh} / 1$, battery voltage range of $2.5 \mathrm{~V} \sim 4.2 \mathrm{~V}$ and maximum output current of 40A. Here, 20 cells in series-parallel connection and another 10 cells in series connection are combined into a lithium-ion battery pack of $36 \mathrm{~V} / 5.8 \mathrm{AH}$ with a total weight of approximately $2 \mathrm{Kg}$ [15].

Figure 1 shows the battery equivalent circuit [16]. The battery internal resistance and capacitance vary according to different values of charge and discharge current, temperature, aging and residual battery power changes. In Figure $1, R_{1}$ is the equivalent resistance for electrode resistance and electrolyte resistance; $R_{2}$ is interface resistance for electrode and electrolyte; $C$ is interface polarization capacitance of electrode and electrolyte; $E$ is battery internal potential; and $V_{o}$ is the battery terminal voltage.

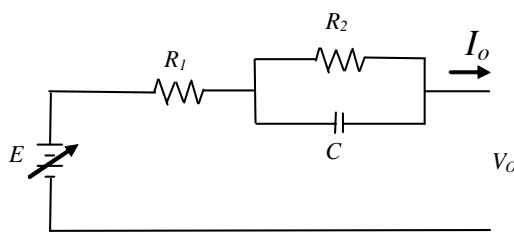

Figure 1: battery equivalent circuit

According to the equivalent circuit of battery, the battery terminal voltage $V_{o}$ can be obtained as Equation (1), where $I_{o}$ is the discharge current and $V_{C o}$ is the initial voltage of capacitor $C$.

$$
\mathrm{V}_{o}=E-\left(R_{1}+R_{2}\right) I_{o}+R_{2} I_{o} e^{\left(-t / C_{2} R_{2}\right)}-V_{C o} e^{\left(-t / C_{2} R_{2}\right)}
$$

\subsection{Chargers and Renewable Energy Design}

Figure 2 illustrates the configuration of an electric bicycle power supply, which includes a main charger and an auxiliary charger. The main charger is designed in a buck converter, capable of converting AC $110 \mathrm{~V}$ utility power to DC $42 \mathrm{~V}$ with charging current of $1 \sim 3 \mathrm{C}$. The charging time lasts approximately 0.5 hours to fully charge lithiumion IBR26700A battery using charging current of $3 \mathrm{C}$ and lasting approximately 1.5 hours to fully charge lithium-ion IMR18650A or IBR26700A battery using charging current of $1 \mathrm{C}$. 


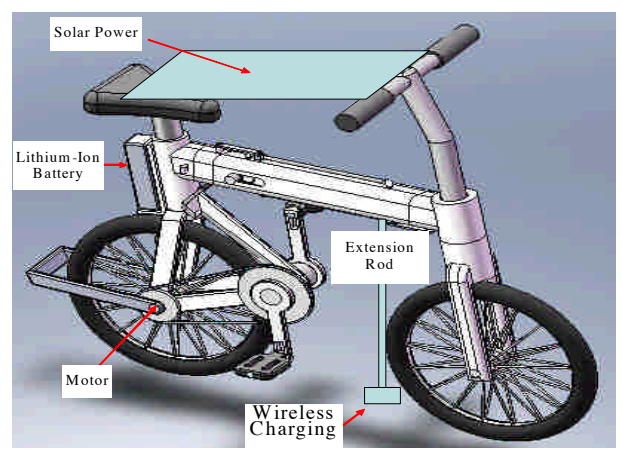

Figure 2: configuration of the electric bicycle power supply

The mileage of the electric bicycle is extended by adding an auxiliary power supply, including solar power system, regenerative brake power system and wireless charging system, as described in the following subsection.

\subsubsection{Solar Power System}

As solar energy is an inexhaustible natural resource, the electric bicycle is applied with solar cells to empower an electric vehicle in order to overcome the limitations of short-distance riding and a long charging time. As sunlight intensity and ambient temperature affect the output voltage and current characteristic curve of solar cells, environmental variations change the maximum output power of solar cells. Thus, operating points of solar cells must be changed according to working environments in order to change the output voltage and current of solar cells so that the maximum output power can be achieved. Such a control method is referred to the maximum power point tracking (MPPT). The electric bicycle in this paper is applied with the design of photovoltaic array that have functions of a sun shade for the bicycle and power generation with MPPT.

\subsubsection{Regenerative Brake Power System}

The power demand of an electric bicycle can be divided into three modes: (I) Accelerating operation and uphill road section, i.e. large power is required; (II) Constant speed operation mode, i.e. lower power is required; and (III) Decelerating operation and downhill road section, i.e. it can deliver regenerated braking power. Despite consuming power in the first and second modes, the electric vehicle can recharge the battery in the third mode.

When the electric bicycle is decelerating in operation or going downhill, regenerative brake power is stored in the battery. When the electric bicycle has an emergency brake, regenerative brake power is stored in an ultra-capacitor. The ultra-capacitor can charge quickly so that the ultracapacitor absorbs a large amount of power from an emergency brake to increase the mileage durability of an electric bicycle and avoid large current from impacting battery. Notably, large charge current to the battery often damages internal materials of battery, resulting in a short battery life.

\subsubsection{Wireless Charging System}

As non-contact electricity transmission method, wireless charging delivers electrical power to battery. Wireless charging systems comprise vehicles wireless charging module and underground wireless charging stations.

Underground wireless charging stations are installed at urban traffic lights for vehicle stopping. These stations consist mainly of power diode rectifier, resonant converter and a primary coil of high-frequency transformer. The power diode rectifier converts utility power to high-voltage direct current. The resonant converter uses LC resonant approach to convert high-voltage direct current into high-frequency and high-voltage alternating currents. This high-frequency alternating current through the primary coil of high-frequency transformer forms magnetic field. Then, if the secondary coil of high-frequency transformer is close, the current can generate magnetic coupling to induce voltage.

The vehicle wireless charging module consists of a secondary coil of high-frequency transformer, impedance matching circuit, power diode rectifier and filter. Secondary coil of the high-frequency transformer induces high-frequency voltage by flux linkage to receive electric power from the charging station. Effectively transferring energy to the load requires impedance matching circuit to achieve maximum power transfer. The power diode rectifier and filter convert high-frequency alternating current to direct current as the electric power source of the charger.

\section{A Smart Battery Capacity Estimation System}

The block diagram of smart battery capacity estimation system is shown in Figure 3. The PIC single chip is the core of the system. Voltage, current and temperature of the battery are measured, aging degree of the battery and charging efficiency are calculated, which are for modifying errors of both coulometric 
measurement method and open circuit voltage method, thus lithium-ion battery capacity of the electric bicycle could be accurately estimated. Figure 4 illustrates the model of the smart battery capacity estimation system. Figure 5 displays the flow chart of the smart battery capacity estimation system, including calculus processes for the open circuit voltage method, coulometric measurement method, current effect, battery aging, temperature and charging efficiency.

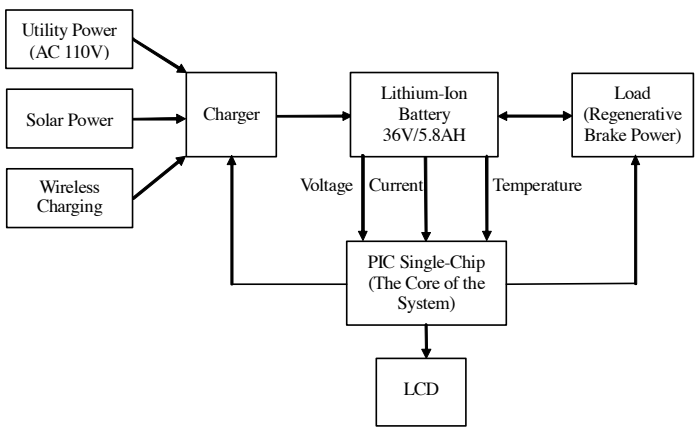

Figure 3: block diagram of the smart battery capacity estimation system

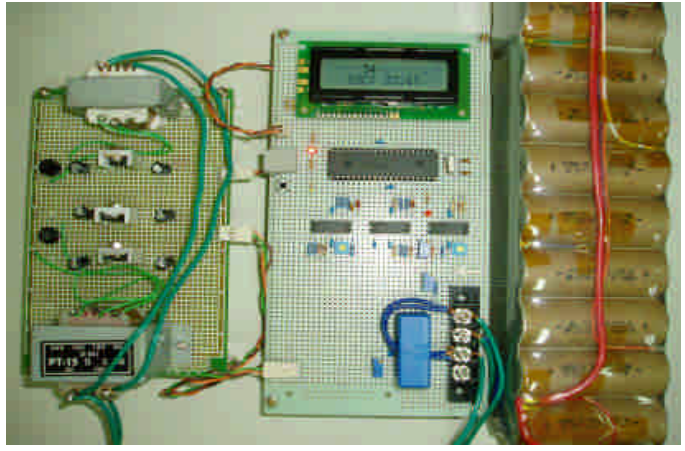

Figure 4: model of the smart battery capacity estimation system

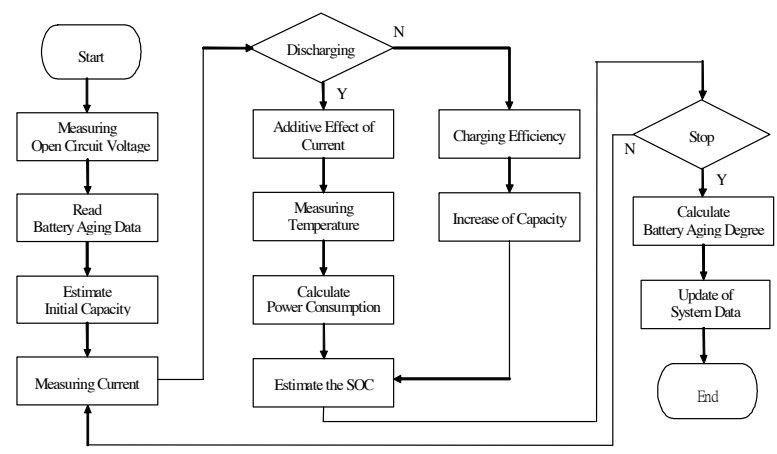

Figure 5: flow chart of the smart battery capacity estimation system

\subsection{Open Circuit Voltage Method}

While the battery is discharging, its terminal voltage drops following the release of electric power. The SOC of the battery can be determined by measuring the battery open circuit voltage. Despite its high accuracy, the open circuit voltage measurement method can only estimate the initial capacity accurately but can not provide an accurate battery capacity during its discharging process. Therefore, once charging or discharging is completed, the battery requires a rest period. For a lithium-ion battery, the rest period lasts more than 1.5 hours as the electrolyte concentration required time to stabilize before the internal capacity of a battery can respond to the output voltage of a battery.

Figure 6 shows the experimental dynamic response diagram of the open voltage of lithiumion battery. The 36V/5.8AH lithium-ion battery was tested with a discharge current of 6.37A. When the battery output voltage was $32.5 \mathrm{~V}$, the discharge action stopped to maintain the battery in an open state; in addition, the voltage change at the lithium-ion battery terminal was observed. The solid line denotes the battery output voltage, while the dashed line represents the discharge current. Approximately 1.5 hours later, the battery output voltage could then maintain a constant value with no changes.

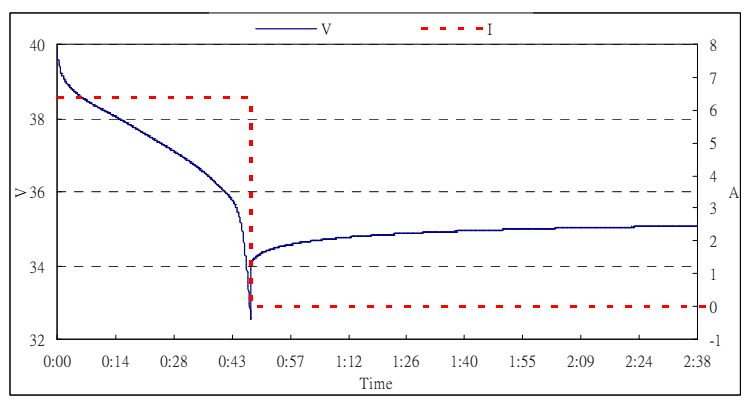

Figure 6: discharging voltage curve

The battery was fully charged initially and maintained in an open state for 1.5 hours. Once the battery terminal voltage was determined, a discharge experiment was performed with a constant current of $1 \mathrm{C}(5.8 \mathrm{~A})$. When the battery capacity reached $\mathrm{SOC}=90 \%$, the released output capacity was $10 \%$ and the discharging time was 6 minutes. The discharge action was stopped to allow the battery to rest for 1.5 hours, and the battery terminal voltage was recorded once again. A discharge action was further conducted in $1 \mathrm{C}$, and the discharge action was temporary stopped for each output of $10 \%$ capacity. After the battery rested for 1.5 hours, the battery terminal voltage was recorded. The above steps were repeated until 
the battery was discharged to the cutoff voltage. Finally, a look-up table of voltage and power was established based on the relationship information of open voltage and capacity.

Next, the output voltage of lithium-ion battery is measured using the built-in $\mathrm{A} / \mathrm{D}$ converter of single-chip PIC 16F877A. The battery capacity is then calculated using the look-up table and interpolation method.

The voltage range of the lithium-ion battery is set as $25 \mathrm{~V} \sim 42 \mathrm{~V}$. As the output voltage of lithium-ion battery covers a wide range, the A/D circuit can be easily implemented. Figure 7 illustrates the measurement circuit of the output voltage of a lithium-ion battery. The output voltage of a lithium-ion battery is initially reduced to $1 / 10$ time in order to allow the output range of voltage measurement circuit to be $2.5 \sim 4.2 \mathrm{~V} ; 2.5 \mathrm{~V}$ is deducted through the operational amplifier; and the voltage is amplified for the input voltage range of $0 \sim 5 \mathrm{~V}$ of the $\mathrm{A} / \mathrm{D}$ converter. The design of this voltage measurement circuit can increase the resolution of the battery voltage signal to be converted into a digital signal. Deducting the lowest operating voltage of $25 \mathrm{~V}$ for the battery, which increase the A/D resolution through the 10bit A/D converter of a single chip. When the analog signal of battery voltage is converted into a digital signal, its resolution can achieve $(42 \mathrm{~V}$ $25 \mathrm{~V}) / 1024=16.6 \mathrm{mV}$, i.e. an increase of 1.47 times as compared to the resolution of $42 \mathrm{~V} / 1024=41.0 \mathrm{mV}$ with no the subtractor circuit.

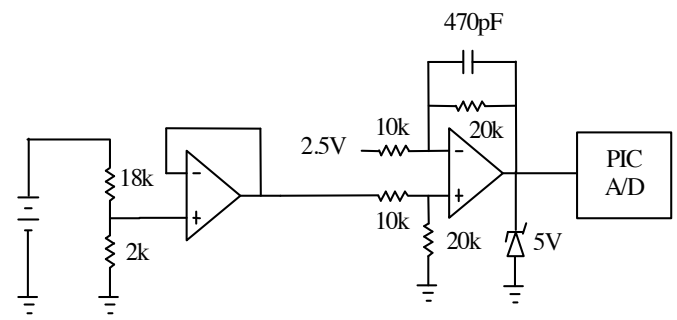

Figure 7: measurement circuit of the output voltage

\subsection{Coulometric Measuring Method}

Coulometric measurement is also referred to as the ampere-hour method, and is currently considered as a highly accurate method. According to the energy conservation theorem, the battery input energy equals the battery output energy. Battery released capacity is the multiplication of output current and discharge time.

$$
Q(t)=Q\left(t_{0}\right) \pm \int_{t_{0}}^{t} I_{o}(t) d t
$$

Where $Q(t)$ denotes the residual battery capacity, $Q\left(t_{0}\right)$ denotes the initial battery capacity and Io denotes the amplitude of the battery charge and discharge currents.

Importantly, although the coulometric measurement method allows us to estimate the battery capacity accurately, it unfortunately generates a large accumulative error if used for a long period of time. Therefore, this paper adopts both the open circuit voltage measurement method and coulometric measurement method coordinately. Importantly, the both methods, as well as discharge current, battery temperature, battery aging and charging efficiency are incorporated into the corrections of battery capacity estimation to develop a highly accurate lithium-ion battery capacity estimation method.

\subsection{Additive Effect of Current}

As the available battery capacity is subject to the load current size, the releasable capacity varies under different discharge currents. For instance, while a larger discharge current implies a smaller battery released capacity, a smaller discharge current implies a larger battery released capacity. A discharge characterization analysis experiment was conducted on lithium-ion battery using Chroma 6312 electronic load to perform a constant current discharge test. Figure 8 shows the experimentally measured curve of discharge currents.

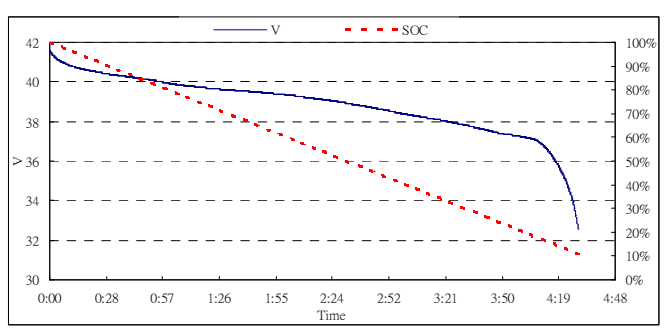

(a) $0.2 \mathrm{C}$

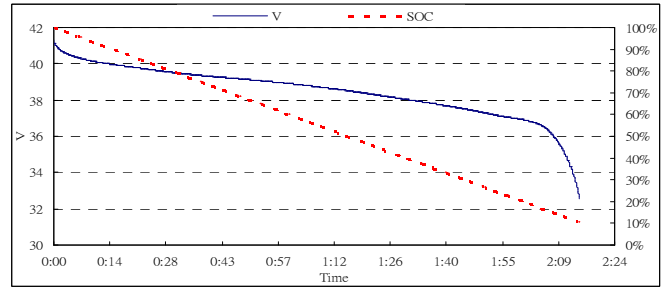

(b) $0.4 \mathrm{C}$

Figure 8: profiles of different discharge rates of (a) $1.2 \mathrm{C}$ (b) $1 \mathrm{C}$ 


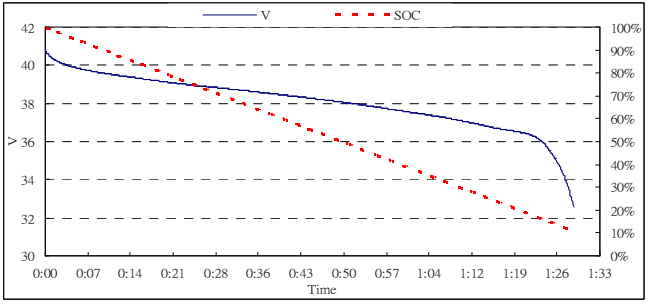

(c) $0.6 \mathrm{C}$

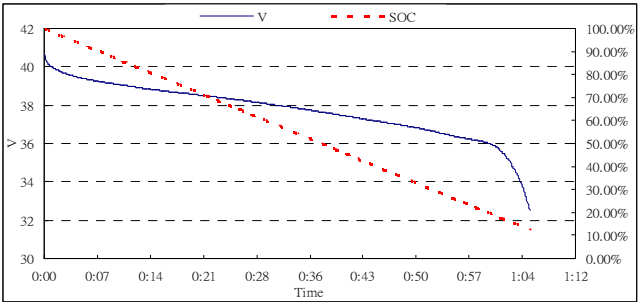

(d) $0.8 \mathrm{C}$

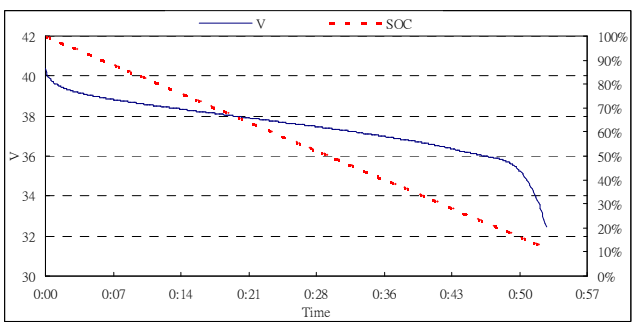

(e) $1 \mathrm{C}$

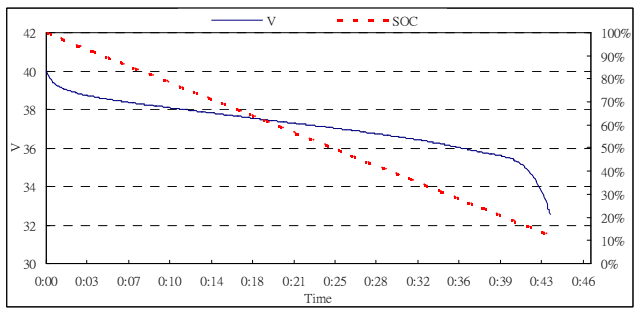

(f) $1.2 \mathrm{C}$

Figure 8: profiles of different discharge rates of (c) $0.8 \mathrm{C}(\mathrm{d}) 0.6 \mathrm{C}(\mathrm{e}) 0.4 \mathrm{C}$ (f) $0.2 \mathrm{C}$

$$
I_{\text {effect }}=Q_{r} / t_{\text {total }}
$$

Equation (3) shows the additive effect of current, where $Q_{r}$ denotes the battery rated capacity, i.e. the released capacity when the saturated battery was discharged with output current of $0.1 \mathrm{C}$ until cutoff voltage. The safety cutoff voltage of a single lithium-ion cell is $2.5 \mathrm{~V}$ or $3 \mathrm{~V}$. Where $I_{\text {effect }}$ denotes the additive effect of the current and $t_{\text {total }}$ denotes the total discharge time.

Figure 8 shows the profiles of various discharge rates. Incorporating the experiment results and the data sheet of the battery provided by the battery manufacture into equation (3) allowed us to obtain the additive effect of the current and the current correction factor (Table 1), including the discharge rate, actual current, released capacity, and rated capacity.

Table 1: additive effect of current $\left(25^{\circ} \mathrm{C}\right)$

\begin{tabular}{|c|c|c|c|c|}
\hline $\begin{array}{l}\text { Discharge Rate } \\
\text { /Actual Current }\end{array}$ & $\begin{array}{l}\text { Released } \\
\text { Capacity } \\
\text { (AH) }\end{array}$ & $\begin{array}{l}\text { Rated } \\
\text { Capacity } \\
\text { (AH) }\end{array}$ & $\begin{array}{c}\text { Additive } \\
\text { Effect of } \\
\text { Current (A) }\end{array}$ & $\begin{array}{c}\text { Current } \\
\text { Correction } \\
\text { Factor } \\
\end{array}$ \\
\hline $0.2 \mathrm{C} / 1.16 \mathrm{~A}$ & 5.786 & 5.8 & 1.163 & 1.002 \\
\hline $0.4 \mathrm{C} / 2.32 \mathrm{~A}$ & 5.780 & 5.8 & 2.328 & 1.004 \\
\hline $0.6 \mathrm{C} / 3.48 \mathrm{~A}$ & 5.734 & 5.8 & 3.520 & 1.012 \\
\hline $0.8 \mathrm{C} / 4.64 \mathrm{~A}$ & 5.718 & 5.8 & 4.706 & 1.014 \\
\hline $1.0 \mathrm{C} / 5.80 \mathrm{~A}$ & 5.703 & 5.8 & 5.899 & 1.017 \\
\hline $1.2 \mathrm{C} / 6.96 \mathrm{~A}$ & 5.664 & 5.8 & 7.127 & 1.024 \\
\hline $3.45 \mathrm{C} / 20 \mathrm{~A}$ & 5.600 & 5.8 & 20.714 & 1.036 \\
\hline $\operatorname{SOC}(t)=$ & $\times 100 \%$ & & & (4 \\
\hline
\end{tabular}

Equation (4) shows the definition of battery residual capacity $S O C(t)$. The SOC is modified by the additive effect of the current, battery temperature, and battery aging effect, as shown in equation (5). Where $S O C(t)$ refers to the present residual power; $S O C\left(t_{0}\right)$, the initial capacity; $Q_{r}$, the rated capacity; $Q(t)$, the residual capacity; $I_{o}(t)$, the discharge current; $f_{l}(I)$, the current correction factor; $f_{2}(T)$, the temperature correction factor; $f_{3}$ (cycle), the battery aging correction factor; and $f_{4}$ (efficiency), the charging efficiency factor.

\subsection{Battery Aging Effect}

The number of battery cycles, discharge depth, discharge current size and temperature affect the battery capacity. Figure 9 shows the relationship between the number of cycles and battery capacity of a lithium-ion battery. When the battery had gone through 200 cycles, the battery capacity remained $80 \sim 85 \%$ of the rate capacity.

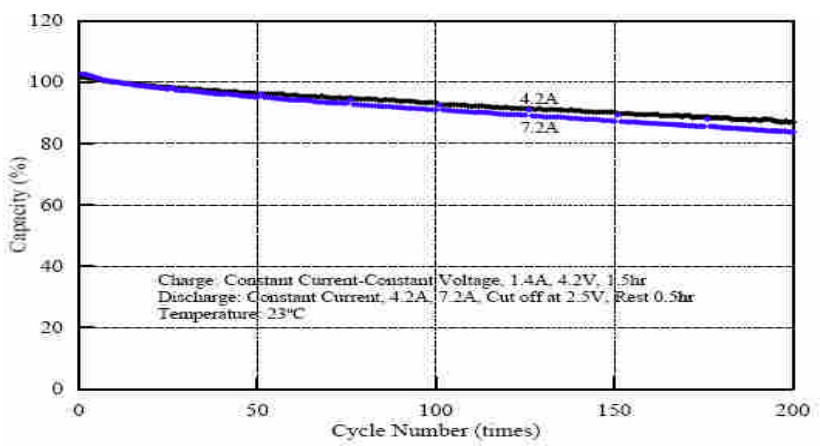

Figure 9: relationship between cycle number and capacity 


\subsection{Temperature}

A rising ambient temperature completes the electrochemical reaction of a battery. Therefore, a smaller battery internal resistance leads to a higher released capacity. In contrast, the battery capacity diminishes. Figure 10 shows the relationship between the capacity and temperature of a lithiumion cell. With a temperature difference of $100 \mathrm{C}$ and $450 \mathrm{C}$, its capacity has a variance of up to $10 \%$.

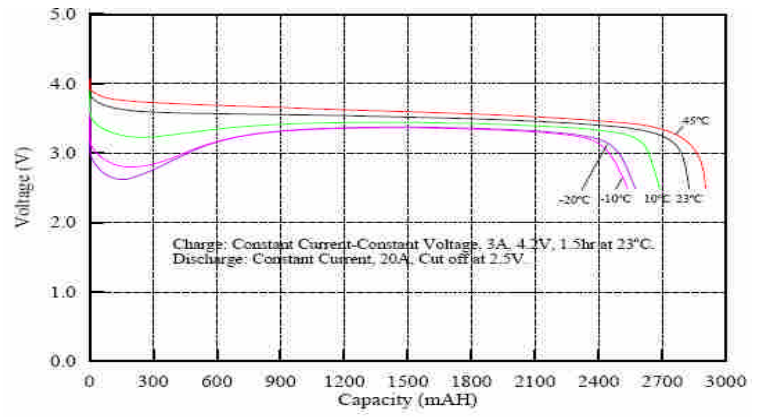

Figure 10: relationship between capacity and temperature

\section{Experimental Results}

The SOC estimation error is defined in equation (6). Where $\mathrm{SOC}_{\text {estimated }}$ refers to the estimation value of battery capacity and $\mathrm{SOC}_{\text {measured }}$ is measured by the equipment. The measured value of SOC was obtained through a direct discharge test method, i.e. by recording the actual capacity released by the battery during the discharge process. The value could provide a standard test value of the residual capacity to serve as a reference for accuracy of this estimation system. The discharge test utilized a constant current and dynamic load current to verify the accuracy of this smart battery capacity estimation system.

$$
E_{\text {rror }}(\%)=\frac{S O C_{\text {estimated }}-S O C_{\text {measured }}}{S O C_{\text {rated }}} \times 100 \%
$$

\subsection{Constant Discharge Current Test}

Following a full charge, the lithium-ion battery rested for more than 1.5 hours and discharged with a current of 6.37A (1.1C) until the output voltage dropped to the cutoff voltage. Figure 11 shows the battery output voltage and current curve diagram. Table 2 compares the battery power estimation value $\left(\mathrm{SOC}_{\text {estimated }}\right)$ and measured value $\left(\mathrm{SOC}_{\text {measured }}\right)$ of $6.37 \mathrm{~A}$ constant load current. The average error is $1.05 \%$, while the maximum error is $2.1 \%$.

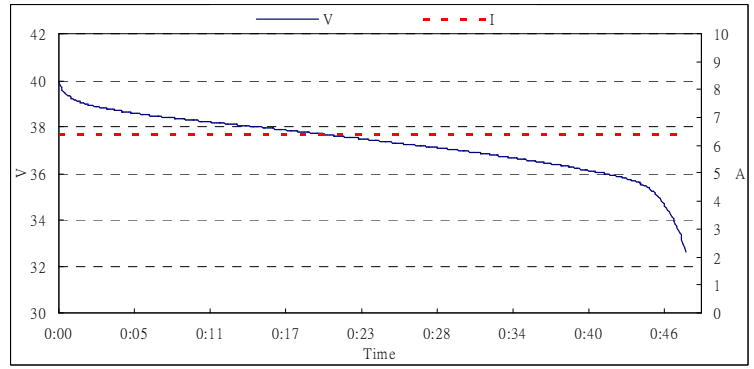

Figure 11: profiles of the battery output voltage and current in a constant load

Table 2: the comparison of $\mathrm{SOC}_{\text {estimated }}$ and $\mathrm{SOC}_{\text {measured }}$ of 6.37A constant load current

\begin{tabular}{cccc}
\hline & SOC $_{\text {estimated }}$ & SOC $_{\text {measured }}$ & $\mathrm{E}_{\text {rror }}(100 \%)$ \\
\hline 1 & 90.6 & 90.7 & -0.1 \\
2 & 81.2 & 81.5 & -0.3 \\
3 & 69.9 & 70.5 & -0.6 \\
4 & 62.4 & 63.2 & -0.8 \\
5 & 53.0 & 53.8 & -0.8 \\
6 & 43.7 & 44.7 & -1.0 \\
7 & 32.4 & 33.9 & -1.5 \\
8 & 24.9 & 26.4 & -1.5 \\
9 & 15.6 & 17.4 & -1.8 \\
10 & 10.0 & 12.2 & -2.1 \\
\hline
\end{tabular}

\subsection{Dynamic Discharge Current Test}

The lithium-ion battery was fully charged, to keep open more than 1.5 hours, and then to $1.2 \mathrm{C}(6.96 \mathrm{~A})$ discharge of 60 seconds and $0.5 \mathrm{C}(2.9 \mathrm{~A})$ discharge of 30 seconds for the cycle until the output voltage drops to the cutoff voltage. The battery output voltage and the actual measured current curve diagram is shown in Figure 12. Shown in Table 3 is the comparison of battery capacity estimation value $\left(\mathrm{SOC}_{\text {estimated }}\right)$ versus actual measured value $\left(\mathrm{SOC}_{\text {measured }}\right)$ of dynamic load. The average error is $1.2 \%$, and the maximum error is $2.2 \%$.

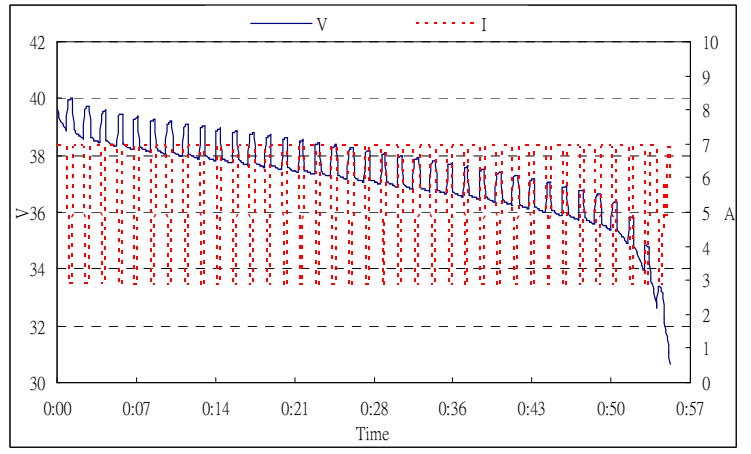

Figure 12: the profiles of the battery output voltage and current in dynamic load 
Table 3: the comparison of $\mathrm{SOC}_{\text {estimated }}$ and $\mathrm{SOC}_{\text {measured }}$ of dynamic load current

\begin{tabular}{cccc}
\hline & SOC $_{\text {estimated }}$ & SOC $_{\text {measured }}$ & $\mathrm{E}_{\text {rror }}(100 \%)$ \\
\hline 1 & 91.6 & 91.6 & 0 \\
2 & 83.1 & 83.5 & -0.4 \\
3 & 75.3 & 75.8 & -0.5 \\
4 & 66.8 & 67.6 & -0.8 \\
5 & 50.6 & 51.8 & -1.2 \\
6 & 42.1 & 43.7 & -1.6 \\
7 & 33.8 & 35.6 & -1.8 \\
8 & 26.0 & 27.8 & -1.8 \\
9 & 17.6 & 19.7 & -2.1 \\
10 & 9.7 & 11.9 & -2.2 \\
\hline
\end{tabular}

\section{Conclusions}

Based on electric bicycle usage features, an electric bicycle is driven around one or two hours daily; the battery is thus largely in an off mode. Therefore, the open circuit voltage method is quite feasible for estimating the initial capacity of batteries. Additionally, although capable of estimating the battery power accurately, the coulometric measurement method generates a large accumulative error after extended use. In addition to integrating the advantages of the coulometric measurement method and open circuit voltage measurement method, the proposed smart lithium-ion battery capacity estimator incorporates the discharge current, battery temperature, battery aging, charging efficiency into capacity correction in order to develop a highly accurate single-chip lithium-ion battery capacity estimation system. According to discharge test results using constant current and dynamic load current, the error is estimated to fall within $3 \%$, demonstrating the high accuracy of the proposed smart battery capacity estimator for electric bicycles.

\section{Acknowledgements}

The author would like to thank the National Science Council of the Republic of China, Taiwan, for financially supporting this research under Contract No. NSC: 98-2218-E-244-001.

\section{References}

[1] E. Karden, S. Ploumen, B. Fricke, T. Miller, and K. Snyder, "Energy Storage Devices for Future Hybrid Electric Vehicles," J. Power Sources, Vol. 168, May 2007, pp.2-11.

[2] O. Coumont, P. Le Moigne, C. Rombaut, X. Muneret and P. Lenain, "Enery Gauge for
Lead-Acid Batteries in Electric Vehicles," IEEE Trans. on Energy Conversion, Vol. 15, No. 3, Sep. 2000, pp. 354-360.

[3] M. Ceraolo and G. Pede, " Techniques for Estimating the Residual Range of an Electric Vehicle," IEEE Trans. on vehicular Technology, Vol. 50, No. 1, Jan. 2001, pp. 109-115.

[4] P. Sabine, P. Marion, and A. Jossen, "Methods for State-of-Charge Determination and their Applications," J. Power Sources, vol. 96, no. 1, June 2001, pp. 113-120.

[5] M. Coleman, C. K. Lee, C. Zhu, and W. G. Hurley, "State-of-Charge Determination from EMF Voltage Estimation Using Impedance, Terminal Voltage, and Current for Lead-Acid and Lithium-Ion Batteries," IEEE Trans. Ind. Elec., vol. 54, no. 5, pp. 2550-2557, October 2007.

[6] J. H. Aylor, et. al., "A Battery State-ofCharge Indicator for Electric Wheelchairs", IEEE Transactions on Industrial Electronics, 1992, pp. 398-409.

[7] F. Pei, K. Zhao, Y. Luo, and X. Huang, "Battery Variable Current-Discharge Resistance Characteristics and State-ofCharge Estimation of Electric Vehicle," in Proc. IEEE WCICA'06, June 2006, vol. 2, pp. 8314-8318.

[8] M. Coleman, C. K. Lee, C. Zhu, and W. G. Hurley, "State-of-Charge Determination from EMF Voltage Estimation Using Impedance, Terminal Voltage, and Current for Lead-Acid and Lithium-Ion Batteries," IEEE Trans. Ind. Elec., vol. 54, no. 5, October 2007, pp. 25502557.

[9] Caumont O., et. al., "Energy Gauge for LeadAcid Batteries in Electric Vehicles", IEEE Transactions on Energy Conversion, Vol. 15, No. 3, Sep. 2000, pp.354-360.

[10] S. Pang, J. Farrell, D. Jie, and M. Barth, "Battery State-of-Charge Estimation," in Proc. IEEE ACC'01, June 2001, vol. 2, pp. 16441649.

[11] A. Delaille, M. Perrin, F. Huet, and L. Hernout, "Study of the Coup De Fouet of Lead-Acid Cells as a Function of their Stateof-Charge and State-of-Health," J. Power Sources, vol. 158, no. 2, August 2006, pp 1019-1028.

[12] D. Doerffel and S. A. Sharkh, "A Critical Review of Using the Peukert Equation for Determining the Remaining Capacity of Lead-Acid and Lithium-Iion Batteries," J. Power Sources, vol. 155, no. 2, April 2006, 
pp. 395-400.

[13] Andre Girard and Mary-Ann Bell, "Blocking Evaluation for Networks with Residual Capacity Adaptive Routing”, IEEE Transactions, vol. 37, No. 12, 1989.

[14] W. X. Shen, C. C. Chan, E. W. C. Lo, K. T. Chau, "Adaptive Neuro-Fuzzy modeling of battery residual capacity for electric vehicles", IEEE Transactions on Industrial Electronics, vol. 49, No. 3, 2002.

[15] http://www.molicel.com

[16] Bernhard Schweighofer, Klaus M. Raab, and Georg Brasseur, Senior Member, IEEE, "Modeling of High Power Automotive Batteries by the Use of an Automated Test System", IEEE Transactions on Instrumentation and Measurement, vol. 52, No. 4, 2003.

\section{Authors}

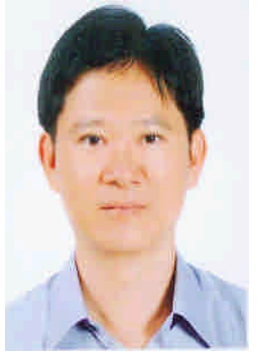

Yow-Chyi Liu received the M.S. and Ph.D. degrees in electrical engineering from National ChenKung University, Tainan, Taiwan, in 1994, and 2005, respectively. He is currently an Assistant Professor in the Department of Electrical Engineering, Kao Yuan University, Kaohsiung County, Taiwan. His research interests include power electronics, electric vehicles, battery, and rapid transit system. 